\title{
The Impact of an Assurance System on the Quality of Teaching and Learning-Using the Example of a University in Russia and One of the Universities in Germany
}

\author{
Peggy Szymenderski ${ }^{1}$, Liliya Yagudina ${ }^{2} \&$ Olga Burenkova ${ }^{3}$ \\ ${ }^{1}$ Technische Universität Dresden, Germany \\ ${ }^{2}$ Kazan National Research Technical University named after A.N. Tupolev-KAI, Russia \\ ${ }^{3}$ Institute of Economics Management and Law, Kazan, Russia \\ Correspondence: Olga Burenkova, Mira street 44 /210, Naberezhnye Chelny, Tatarstan, 423819, Russian \\ Federation. Tel: 8-552-393-837. E-mail: chelnyola@mail.ru
}

Received: July 10, 2015

Accepted: August 6, $2015 \quad$ Online Published: September 17, 2015

doi:10.5539/hes.v5n5p15

URL: http://dx.doi.org/10.5539/hes.v5n5p15

\begin{abstract}
In this paper we consider the question of how quality assurance can have a real, positive impact on the quality of teaching and learning at universities, considering the realities of different systems - the system of control and the system of quality culture - in using the example of two universities: the KNITU-KAI in Russia and the TU Dresden in Germany. The study involved 40 lecturers of technical courses and 120 third-year students of technical courses from both universities. The authors put forward a working hypothesis that quality assurance has a positive effect on the quality of teaching and learning if it carries out its informational, motivational and administrative functions. The results have shown that the aforementioned functions are not fulfilled by both universities and a special organizational culture is not the only condition that must be met for effective evaluation efforts. In order to fulfill motivational, informational and administrative functions, it is important as well that the quality assurance system is transparent and that all participants see that the surveyed data and results lead to measures for quality development. It is equally important that all university members participate in the process of quality assurance.
\end{abstract}

Keywords: quality of teaching and learning, evaluation, quality assurance system, quality culture, improvement

\section{Introduction}

\subsection{Actualizing the Problem}

For the time being, European higher education exists in the context of the Bologna process. The quality of teaching and learning at higher education institutions is one of the key focuses which results in the establishment of national quality assurance systems in European countries.

European cooperation in quality evaluation continues to be regarded as a prerequisite for creating the European zone of higher education and for promoting the European higher education system throughout the whole world. By 2010, European countries had achieved disparate results, and, while giving unqualified credit to the Bologna process for constructing the European system of teaching quality assurance, a number of researchers are of the opinion that the features specific to the national education systems still exercise a huge influence on introducing changes into quality assurance processes.

\subsection{Exploring the Importance of the Problem}

Publications in the field of quality evaluation in higher education institutions abound in both recommendations aimed at improving national higher education quality assurance systems on the basis of benchmarking (Note 2) and in skepticism about their implementation being capable of leading to increased international trust for the quality of teaching and learning in the short term.

We are in agreement with Harvey (2010) and Westerheijden, Hulpiau and Waeytens (2006), who believe that, during the last twenty years, in quality evaluation, researchers have been avoiding actually exploring the inner nature of higher education quality and it has been only in some recent works that emphasis has shifted from 
general perspectives to practical application and understanding of the real value of all these efforts related to quality assurance.

Huisman and Westerheijden, while reviewing the emergence of quality issues in the Bologna process, cast doubt on the capability of the efforts undertaken to improve the teaching quality accessible to students, and to help universities in quality management.

According to Motova (2010), Harvey (2006), Newton (2010), and Westerheijden, Stensaker and Rosa (2007), quality evaluation in the Bologna process, which includes the institute of accreditation, is, as a matter of practice, aimed at monitoring and receiving reports from universities rather than at quality improvement.

An understanding of the impact of the evaluation process, under conditions of active international activity aimed at developing quality assurance systems at all levels in the $21^{\text {st }}$ century, becomes vitally important for education development and requires that the effectiveness of the measures taken be studied. Once there is political recognition of the need for such research and the need for promoting such research, there remains a methodological problem of determining the direct influence of evaluating the quality of teaching and learning without distortion caused by other factors.

Depending on the orientation of the quality assurance systems to control or improve quality has determined ambivalence, at the conceptual level, between the technocratic and cultural approaches, and has become the basis for shaping the technocratic approach to quality evaluation.

As is known, in the technocratic approach, universities are considered to be some kind of production operation which manufactures a product compliant with pre-established standards. The production operation is organized in accordance with a top-down approach in such a way as to comply with these standards. Lecturers are not interested in the quality of teaching and learning; they are in need of external control and are subsequently managed by making their remuneration dependent on the results achieved.

The other approach to the issues of quality evaluation in higher education institutions can be, with certain reservations, referred to as cultural. It involves scientific research and practice based on the conviction that real quality can be attained only when there is well-developed quality culture in place at all the levels and with all the participants in the educational process.

The concept of quality culture is based on the so-called bottom up approach, which consists of initiating measures aimed at improving quality in the organization at large from the personnel level.

Within the concept of quality culture, lecturers do not need external control. The main mechanisms of quality culture are self-reflection and concern about the quality from each member of the educational process. In the concept of quality culture, evaluation is regarded as a tool to ensure feedback for strategic planning in the area of quality improvement in teaching and learning. The only consequence of this kind of quality evaluation must be improvement rather than control and subsequent punishment which are incompatible with academic values.

\section{Materials and Methods}

\subsection{The Goals and Tasks of the Research}

The aim of this research is to define the conditions for shaping the capability of quality assurance systems practiced at universities to impact the quality of teaching and learning. This study uses the actual situations at two universities: KNITU-KAI in Russia and the TU Dresden in Germany.

The present article is aimed at accomplishing the following tasks:

- Describing the quality assurance systems in both universities as part of national quality assurance systems in higher education institutions;

- Analyzing the impact of external and internal systems of quality assurance on the quality of teaching and learning in the perception of university lecturers and students;

- Analyzing the impact on the quality of teaching and learning exercised by a certain type of quality evaluation - evaluation of teaching quality by students.

- Elaborating upon recommendations aimed at improving the systems of quality assurance for universities.

\subsection{Theoretical and Empirical Methods}

The choice of research methods is determined by the research logic: from general to specific. In this particular case a combined method is used: completion of questionnaires and semi-structured interviews.

The first part of the research is devoted to analyzing the influence exercised by national and internal quality 
assurance systems in teaching and learning as perceived by university lecturers and students as key participants in the educational process (Note 1). This analysis is important to determine general values, expectations and conditions in terms of quality assurance in higher education institutions.

The questionnaire method was used in the second part of the study. This part was devoted to researching a specific type of quality evaluation in which the quality of teaching is evaluated by students.

Questions 1, 2 and 3 of the questionnaire (Appendix A) are targeted at revealing the lecturers' and students' opinions on the students' ability to evaluate teaching quality.

Questions 4 and 5 of the questionnaire are devoted to determining the impact of certain criteria on the objectivity of the students' evaluation.

The motivational function of polling manifests itself in an improvement of the lecturer's performance influenced by the results of the students' evaluation of different disciplines (Questions 6, 7, 8 and 9 of the questionnaire).

The administrative function is related to the use of evaluation results for management decisions made with regard to lecturers' careers, remuneration of their work, extension of their contracts, etc. (questions 10, 11 and 12).

The informational function consists of providing stakeholders with information about the quality of teaching and learning. This is of essential interest for students during the decision-making process regarding the choice of the university, discipline, etc. (question 13 of the questionnaire).

\subsection{Empirical Basis of the Study}

The research data were collected by the authors themselves directly at the universities during the 2013/2014 academic year. Bases for research are two universities having similar statuses in the national education systems: KNITU-KAI and TU Dresden.

KNRTU-KAI is one of the leading Russian institutions in aircraft engineering, engine and instrument production, computer science, radio and telecommunications engineering. KNRTU-KAI is 1 of 29 universities selected from all Russian universities which were awarded the prestigious title "National Research University". Total number of students-18 000 .

The TU Dresden is one of 11 German universities which were named "excellence universities". The TU Dresden is a multidisciplinary university, offering degree programs in five schools: natural science, the humanities and social science, engineering, civil and environmental engineering and medicine. Total number of students- 37 000 .

Students and lecturers from technical universities were surveyed only to ensure comparability of results. Second and third-year students and lecturers of technical disciplines were selected. At both universities students and lecturers do not have explicit experience in quality management. The authors wanted to get an insight into how well the proceedings of quality assurance were already known. Based upon this the extent to which a quality culture can develop can be assessed.

At KNRTU-KAI University 20 lecturers conducting technical courses and 20 third-year students taking technical courses were surveyed based on semi-structured interviews (for the quality assurance of teaching and learning in general). Next, 20 lecturers teaching technical courses and 100 third-year students taking technical courses were surveyed by questionnaire (for course evaluation by students as a particular type of quality evaluation).

At the TU Dresden only ten teachers could be obtained for semi-structured interviews. Because students were unwilling to participate in the interview, they were asked to answer the questions of the semi-structured interview in an online questionnaire. Mainly open-ended, but also a few closed-ended questions were asked. 24 third-year students in technical courses participated. 23 teachers completed the questionnaire about course assessment by students. 100 second and third-year students in technical courses were also surveyed by questionnaire.

\subsection{Characteristics of the Quality Assurance Systems of KNRTU-KAI in Russia and the TU Dresden in Germany}

The current Russian education system is aimed at assuring the quality of teaching and learning in higher education institutions, compliant with the requirements of the Bologna process. This occurs through the institutions of state control and evaluation in collaboration with independent quality evaluation of teaching and learning.

For the purposes of assuring the quality of teaching and learning, the following mechanisms are used:

- licensing of educational activities; 
- state accreditation of educational activities;

- state control (supervision) in the field of higher education;

- independent evaluation of the quality of teaching and learning;

- public accreditation of higher education organization;

- professional public accreditation of educational programs;

- self-evaluation of educational organization.

Russian law does not provide the non-governmental types of evaluation with any function of guaranteeing the quality of teaching and learning. This therefore enhances the role of government control and oversight in the sphere of higher education and assigns to the government the role of the principal guarantor of the quality of teaching and learning.

The quality of teaching and learning at KNRTU-KAI is therefore primarily ensured by government accreditation. By 2009 the accreditation system in Russia had been formed in accordance with the "Standards and Guidelines for Quality Assurance in the European Higher Education Area (ESG)". Underlying the evaluation of the quality of teaching and learning is compliance with federal state educational standards. Work by external experts at the university is preceded by internal self-evaluation procedure.

The following analytical tools are used for quality analysis of the study programs through accreditation:

- analysis of the organizational documents, the self-evaluation reports, and the university statistics database;

- analysis of student documents (curriculum, teaching materials, materials for the assessment of students' knowledge, educational technology, etc.) for compliance with federal state educational standards;

- external expertise by employers;

- test of students' knowledge on materials prepared by the Department of the Ministry of Education and Science of Russia;

- interviews with students and teachers, etc.

The last state accreditation at KNRTU-KAI was in 2012. As a result, 37 generalized groups of programs, which the University provides, were accredited.

But, as national and international practice shows, government control of the quality of teaching and learning cannot fully ensure that modern principles of quality evaluation are carried out. Therefore, as early as 2007 , the administration of KNRTU-KAI initiated the implementation of an internal university quality management system as the most important factor to improve the quality of the university's activities.

In 2008 , the quality management system of the university was certified for the first time, while in 2012 it was evaluated and found to be in accordance with the requirements of ISO 9001: 2008.

Strategic oversight of the quality management system at the university is provided by the rector. In order to manage systematic activities to ensure continuous quality improvement of educational services, a quality control office has been set up.

Under the conditions of stringent government control of the quality of education, a significant amount of effort from the quality control office is directed at testing the students' knowledge. Testing is conducted with the hope of obtaining an objective evaluation of the content, level, and quality of learning for conforming to the requirements of the federal government educational standard.

In 2015, KAI-KNRTU participated in the introduction of a new tool for the evaluation of teaching and learning which independently evaluates students' knowledge during the current exams. In this procedure, written exams are given and assessed by teachers from other universities. Such an approach, according to the organizer-the Ministry of Education and Science of Russia - should allow a more objective assessment of the knowledge of students.

In Germany, instruments of internal and external quality assurance at higher education institutions have been systematically used since the early 1990s (Banscherus, 2011). The "Standards and Guidelines for Quality Assurance in the European Higher Education Area (ESG)" also provide the framework for internal and external quality evaluation (Joint Committee on Standards for Education Evaluation 2006).

A high quality of teaching and learning and quality improvement are a permanent part of the mission statement of TU Dresden. Therefore, in 2009 the TU Dresden began to develop a comprehensive quality management 
system for teaching and learning under the broad participation of university staff and students. The quality management system includes teaching guidelines, which are the foundation for practical demands of high quality in teaching and learning and which have to be implemented in each study program. These teaching guidelines and the minimum standards of quality of teaching and learning, which are given by the Accreditation Council (Akkreditierungsrat 2009), are the basis for the quality analysis of the study programs which are conducted by the Centre for Quality Analysis (ZQA). The ZQA was established as a central scientific unit in 2011 and it is commissioned to evaluate the quality in teaching and learning of the study programs of the TU Dresden.

After the implementation of both the quality management system and the first evaluations of study programs, the rectorial board has decided to initiate the system accreditation. The system accreditation focuses on higher education institutions' own internal quality assurance systems for teaching and learning. Positive system accreditation certifies that the higher education institutions' quality assurance system is able to ensure the achievement of learning outcomes and a high quality of study programs (Akkreditierungsrat, 2009). The system accreditation should replace the program accreditation at the TU Dresden. In the context of program accreditation a study program is reviewed in order to analyze if technical, structural and organizational study standards are met. The process of system accreditation was completed in March 2015. The TU Dresden has passed successfully. Now it is certified that the TU Dresden has a functioning internal quality assurance system for teaching and learning.

Different analytical tools are used for the quality analysis of the study programs:

- The statistical data of the TU Dresden and the analysis of existing documents (e.g. teaching-reports, accreditation-reports) are used for illustrating and describing ef general trends in the study programs.

- The analysis of the study documents are used for the evaluation of the curriculum, study regulations and module description.

- The results of the lecture evaluations and the student surveys are used to describe the conditions of teaching and learning and the didactics of lectures and seminars. Lecture evaluation is characterized by standardized questionnaires on lectures, tutorials, seminars or lecture series. The student surveys are conducted as online surveys (quantitative) or qualitative group discussions. This is dependent upon the number of students who enrolled in the study program.

- Graduate surveys provide a retrospective viewpoint of their studies and their transition into a career.

- The lecturers' surveys provide subjective perceptions of the conditions of teaching and learning in the study programs.

- Assessments from experts with professional experience and from experts from specific academic disciplines.

The results of the analyses go into an evaluation report in which the strengths and weaknesses of the program are pointed out. Despite the challenges which result from the variety of methods are used, the instruments for quality assurance lead to a systematic consideration of heterogeneous ideas of quality in teaching and learning of various stakeholders. A wide empirical basis can provide quality development.

The non-governmental accreditation is not supported in Russia. In Germany, the universities can develop their own quality assurance systems within the framework of university autonomy. From this derives a crucial difference between the two quality assurance systems of Russia and Germany, and this difference lies in the quality standards which are defined by the government of the Russian Federation. This greatly minimizes the autonomy of Russian universities whereas German universities have more autonomy to define their quality standards for teaching and learning.

Due to the strong state control in Russia, lecturers and students hardly take responsibility for the quality of teaching and learning. At the TU Dresden university members, and especially students, have been involved in the development of the quality management system from the beginning. Therefore the university members obtained a greater confidence in the quality evaluation of teaching and learning. It will be interesting to see whether or not these assumptions be reflected in the results of this survey.

Another difference lies in the analytical instruments. At KNRTU-KAI the quality control office tests students' knowledge. It is checked whether their objectively valued knowledge meets the state quality standards. Within the framework of the government accreditation at KNRTU-KAI similar analytical tools are used such as TU Dresden. But TU Dresden attaches more importance to the opinion of students, graduates and teachers, which are obtained from the surveys. A wide empirical basis is fundamental, which allows describing the quality of teaching from different perspectives. 
These Universities' brief descriptions allow us to assume that the system of quality assurance in KNRTU-KAI is based on a technocratic approach that is driven by an external control. The system of TUD is closer to the cultural approach and is based on internal evaluation.

Next, we will try to determine the impact of these different quality assurance systems on the effectiveness of teaching quality, considering the realities in Russia (KNRTU-KAI) and Germany (TU Dresden).

\section{Results}

During the study of the influence exerted by external and internal quality assurance systems on teaching quality, from the perspective of Russian lecturers and students, we revealed that in Russian higher education institutions, the general idea lecturers have about quality of teaching is rather steady.

Students primarily consider the teaching quality as the quality of the university, manifesting in the quality of its human resources, information resources and that of education process.

Answers to the question concerning teaching quality indicators correlate with the interviewees' representations of the essence of the teaching quality and represent the following list of higher education quality evaluation elements: knowledge, students' skills, number of professors with $\mathrm{PhD}$ degrees, lecturers' practical experience, employment of graduates, etc.

Russian lecturers and students suggest as an aim of quality evaluation in higher education institutions primarily control over education process. It may be assumed that this kind of vision is predicated by the historically practiced domination of the government over education, which manifests itself, among other things, in the commonly stringent control of quality in teaching and learning from top to bottom. Certain lecturers, referring to the quality management principles, do recognize, as an aim of quality evaluation, the feedback between the participants of education process.

In their answers to the question "What types of teaching quality assurance do you know?" the majority of respondents, primarily students, substituted the concept of "methods" with the concept of "types", referring to testing, examination, etc.

All the lecturers mentioned being knowledgeable about the internal quality assurance system at the KNRTU-KAI, identifying it with the certified quality management system; however, they voiced their skepticism about the effectiveness of its impact on the quality of teaching and learning.

Almost all the students found it difficult to define the influence of the external evaluation on the quality of teaching and learning. Since the university underwent a mandatory process of governmental accreditation two years ago, the students identify the external quality evaluation with this process and hold the opinion that they did not see any changes following this accreditation.

Governmental accreditation is perceived by the lecturers as an authorizing measure only, necessary for the university to exist.

About one third of lecturers hold the view that internal quality evaluation is more effective, as, firstly, it is considered by lecturers as an element of control resulting in reputational consequences. Secondly, it is due to precisely this that the university remains responsible for the quality of teaching and learning.

All the lecturers are of the opinion that, apart from the governmental type, there must also be other types of external independent assurance. From the perspective of the majority of them, users of educational services and educational results, i.e. students and employers, should be subject to this assessment. However, the lecturers are unanimous that neither students nor employers are prepared to participate in quality evaluation procedures, as they lack appropriate expertise.

Students list as being subject to evaluate lecturers, administration of structural divisions, university, the Ministry of Education and Science, and it is only two of them who extended this list to include students.

In consideration of the interpretation of the following results from the TU Dresden, it should be noted that the underlying survey in the present paper was conducted on students and teachers of technical programs who had little involvement in the internal quality assurance system of the TU Dresden. At the moment, the first engineering programs are going through the evaluation process. Therefore, it is not surprising that students and teachers are not familiar with the internal quality assurance system of the TU Dresden - nobody deals with it on an abstract level. That is why the following results can only be understood as a first insight into the subject.

The analysis of the impact of quality assurance systems on the quality of teaching and learning, as interpreted by lecturers and students from TU Dresden, shows that lecturers see lecturers' motivation, lecture style and didactic 
competence as the most important factors for-high quality in teaching. Motivated teachers with enthusiasm for their discipline are important for students. The lectures should be taught by pedagogically competent and academically qualified teachers.

Altogether, the quality of teaching and learning is manifested in the quality of human resources, information material about the course content, the structure of teaching content and the level of students' motivation for independent study.

The interviewed lecturers describe the aims of quality assurance in teaching in particular in relation to their experiences with lecture evaluation. It is the most elaborate procedure of quality assurance at the TU Dresden. Lecture evaluation is has been conducted at the TU Dresden since 1998. That's why lecturers see higher education quality assurance as an important possibility for students to give feedback about lectures and seminars, and believe that they must take it seriously. Students, and also lecturers, see the main objective of teaching quality assurance as being able to define the shortcomings of teaching and to generate improvement in the quality in teaching and learning. It can increase the university's appeal. Besides, it is important to establish uniform quality objectives which have to be met by lecturers and which result in comparability. Students emphasize control over educational process as an aim of quality assurance.

When asked about types of quality assurance in teaching and learning — as would be expected - the majority of the asked students indicated that they didn't know any type of quality assurance. Some students list the evaluation of lectures and seminars by students at the end of the semester; all interviewed lecturers participated. Only half of the interviewed lecturers mentioned program accreditation-most of them have experienced a program accreditation in their faculty. Only two lecturers list system accreditation as a type of quality assurance; only one in connection with the system of quality assurance at the TU Dresden. Now, since the system accreditation is successfully completed, it is expected that more teachers and students take note of the internal quality assurance system of teaching and learning of the TU Dresden.

The internal quality assurance system is known only by those teachers and students who have already been involved in the procedure. But also some of them, who do not know the internal system, believe that it can have a positive impact on teaching quality. Therefore certain prerequisites must be met, e.g. seriousness, real positive improvements, transparence.

Lecturers and students see the benefit of external quality assurance - they are referring to program accreditation and peer review - in the independent and neutral perspective of external experts, which prevents "operational blindness". In addition, comparability and competition between universities is created. For that reason, it can be concluded that the system accreditation certified internal quality assurance system of teaching and learning at the TU Dresden would be an accepted method of quality evaluation.

Students express the opinion that the results of quality evaluation should have an impact on the following decisions: appointment of lecturers (more than two thirds of students), financial and human resources in faculties and study programs (half of the asked students), continuation/discontinuation of study programs (nearly half) and salary of lecturers (one third). Two students listed other aspects: a mandatory participation of lecturers in didactic education and recruitment of scientific staff. In the lecturers' perspective, quality evaluation should have an impact on lecturers' participation on didactic education and development of teaching methods as well as on the allocation of financial and human resources.

Half of the students asked couldn't estimate the efforts that the TU Dresden made to establish an internal quality assurance system and to achieve a quality culture. But there are also many students (10) who believe that there is a need to establish a special organizational culture to achieve a well-functioning quality management system. An important condition is the commitment of all members of the university, in particular of lecturers. Lecturers see a special organizational culture as an important basis, which has to be characterized by competition not only in scientific research (e.g. through funds for research projects, research awards, grants for research fellowships) but also in teaching.

Thus, our results suggest that the TU Dresden's system of quality assurance is much closer to the evaluation based on the quality culture - which has been described in the theoretical framework - than the KNRTU-KAI system.

\section{Discussion}

At both universities the process of internal quality evaluation is preferred over the external procedure. Thereby, Russian lecturers and students emphasize the need for greater autonomy of the university and less governmental control in this procedure. German lecturers and students deal with internal quality evaluation in a more detailed 
way and list requirements which should be met, such as seriousness, implementation of recommendations, consideration of specifics of the programs, and quality evaluation not being a burden. With an internal quality evaluation of teaching and learning, the specifics of the university and the degree programs can be considered in a greater extent, according to the students and lectures asked.

The external quality evaluation is considered as a useful complement to the internal procedures at both universities. But at KNRTU-KAI students and employers admitted to an incapability to evaluate the quality of teaching and learning at universities. At the TU Dresden, the function of external experts is particularly seen in the prevention of operational blindness and mistakes as a matter of routine.

For a successful implementation of the quality assurance system as a whole, it has been shown that a special organizational culture plays an important role. A high quality of teaching must be a common value. This is true for both universities.

But there are some aspects which are opposed to the development of a quality culture and which are particularly important in terms of the implementation of the administrative function of quality evaluation. Due to the governmental control in the Russian Federation, only financial results and publications of university staff should be of importance, not the quality of graduates, according to the surveyed lecturers. In this case, a "good" quality of teaching arises out of lecturers' fear, not out of their motivation. At the TU Dresden too few incentives exist for lecturers to become more committed to improving the quality of teaching, according specifically to the teachers asked. Other standards of quality must be defined, which in turn have an effect on the motivational function of quality assurance. To meet the informational function of quality evaluation, for instance, the TU Dresden organized a celebration on the occasion of the system accreditation, which TU Dresden successfully passed.

It can be summarized for both universities that lecture evaluations are an important instrument of the quality assurance system, because it provides the possibility for students to participate in teaching quality management. With the introduction of the lecture evaluations as a tool for quality assurance, attention will be given to some requirements which will particularly motivate all university members to participate in the process of quality assurance. As Rindermann and Kohler (2003) have already shown, quality assurance leads to an improvement of teaching quality if beneficial conditions exist, especially the explanation of the evaluation results and, based on that, counseling of teachers, training in didactics, higher institutional weight of teaching in comparison to research, and the creation of incentives for a high quality in teaching.

A crucial difference between the two universities is that the students of the TU Dresden have and claim a greater transparency regarding the results of course evaluations. So, the students of the TU Dresden and the KNRTU-KAI have different demands regarding the informational function of quality evaluation. Moreover, students of TU Dresden are more critical of their own power to evaluate, particularly with regard to their regular attendance in lectures and seminars. At KNRTU-KAI the academic progress of students have a greater influence on the evaluation results.

\section{Conclusion}

As shown by the results of the research, students and lecturers deal with quality assurance only if they are directly involved in the process. They do not do this on an abstract level. The acceptance of quality assurance by students and lecturers will grow as the number of quality analyses of degree programs conducted rises, as shown by these results. This is the basis for the development of quality culture. But a special organizational culture is not the only condition to be met for an effective quality evaluation process. In order to fulfill motivational, informational and administrative functions, it is also important that teaching is given a higher institutional value in comparison with the research. Incentives for greater engagement in teaching are necessary as well. Defined quality standards facilitate control and comparability in the development of quality. Experience has shown that lecturers at KNRTU-KAI and the TU Dresden fear the bureaucracy of quality evaluation. It has to make sure that the evaluation process does not create data cemeteries.

The quality assurance system should be transparent and all participants should see that the surveyed data and results gathered lead to measures for quality development. Lecturers expressed their apprehension that the results of the evaluation process are used to select worthy universities and legitimize cuts in resources. This it takes a lot of confidence, which can only be achieved by-very high transparency in the quality assurance procedure. That is why it must be a "bottom-up" process. Controlling compliance with quality standards is important, but it is equally important that all university members participate in the process of quality evaluation in teaching and learning. 


\section{Acknowledgments}

We thank Prof. Karl Lenz, Holly Brown, Franziska Hennig, Iryna Moskalenko and Pamela Spehr (TU Dresden) for contributing to preparation of the article.

\section{References}

Akkreditierungsrat. (2009). Rules for the Accreditation of Study Programs and for System Accreditation. Beschluss des Akkreditierungsrates vom 08.12.2009, zuletzt geändert am 20.2.2015, Drs. AR 20/2013. Stiftung zur Akkreditierung von Studiengängen in Deutschland.

Banscherus, U. (2011). Quality Assurance in Higher Education in the dispute of policy in higher education. Frankfurt, Gewerkschaft Erziehung und Wissenschaft.

Vettori, O., Lueger, M., \& Knassmüller M. (2007). Dealing with ambivalences. Strategic options for nurturing a quality culture in teaching and learning (pp. 21-27). A selection of Papers from the 1st European Forum for Quality Assurance, 23.-25.11.2006, München. European University Association.

European University Association. (2005). Developing an Internal Quality Culture in European Universities. Report on the Quality Culture Project Round II -2004. Retrieved August 3, 2015, from http://www.eua.be/eua/jsp/en/upload/QCII\%20Report\%2030.03.05.1115967574238.pdf

European University Association. (EUA) (2005). Developing an Internal Quality Culture in European Universities. Report on the Three Rounds of the Quality Culture Project 2002-2003. Retrieved June 25, 2013, from http://www.eua.be/eua/jsp/en/upload/QC1_full.1111487662479.pdf

Harvey, L. (2006). Overview of a discussion between representatives of external quality assurance agencies. Quality in Higher Education, 12(3), 287-290.

Huisman, J., Rebora, G., \& Turri, M. (2006). The effects of quality assurance in universities empirical evidence from three case Studies. AAVV EUA Bologna Handbook EUA Retrieved August 3, 2015, from http://www.eua.be/typo3conf/ext/bzb_securelink/pushFile.php?cuid=2379\&file=fileadmin/user_upload/file s/QAForum_2006/GS_III_5_Rebora_and_Turri.pdf

Huisman, J., \& Westerheijden, D. (2010). Bologna and quality assurance: progress made or pulling the wrong cart? Quality in Higher Education, 16(1), 63-66.

Joint Committee on Standards for Educational Evaluation. (2006). Handbook of Evaluation Standards. The Standards of the “Joint Committee on Standards for Educational Evaluation". Wiesbaden: VS Verlag für Sozialwissenschaften.

Minelli, E., Rebora, G., \& Turri, M. (2008). The fifteen year evaluation experience in Italian universities with its crisis factors and a desire for Europe. Implementing and using quality assurance: strategy and practice (pp. 68-74). A selection of papers from the 2nd European quality assurance forum. 15-17 November 2007. Belgium: European University Association.

Motova, G., \& Pykko, R. (2010). Russian Higher Education and European Standards of Quality Assurance. European Journal of Education, Special Issue: Russian Higher Education and the Post-Soviet Transition, $47(1), 25-36$.

Newton, J. (2010). A tale of two Qualities: reflections on the quality revolution in higher Education. Quality in Higher Education, 16(1), 51-53.

Pratasavitskaya, H., \& Stensaker, B. (2010). Quality management in higher education towards a better understanding of an emerging field. Quality in Higher Education, 16(1), 37-50.

Rindermann, H., \& Kohler, J. (2003). Does Evaluation and Consulting improve Quality of Instruction? Test of an Evaluation-Consulting-Model. Psychologie in Erziehung und Unterricht, 50(S), 71-85.

Roznayi, C. (2009). The quality revolution. Quality in Higher Education, 16(1), 77-79.

Wilen-Daugenti, T. (2010). 21st Century Trends for Higher Education: Top Trends. $26^{\text {th }}$ annual conference on distance teaching and learning. Retrieved August 3, 2015, from https:/www.cisco.com/web/about/ac79/docs/wp/Top_trends_in_Education_White_Paper.pdf

Vroeijenstijn, A. I. (1995). Improvement and accountability: Navigating between Scylla and Charybdis (p. 188). Higher Education Policy Series 30. London; Bristol, Pa.: J. Kingsley Publishers.

Westerheijden, D. F., Hulpiau, V., \& Waeytens, K. (2006). Lines of Change in the Discourse on Quality Assurance an Overview of Some Studies Into what Impacts Improvement. 28th Annual EAIR 1Forum. Rome, 
Italy. Retrieved August 3, 2015, from http://www.utwente.nl/bms/cheps/publications/Publications\%202006/Westerheijden.pdf

Westerheijden, D., Stensaker, B., \& Rosa, M. J. (2007). Assurance in Higher Education: Trends in Regulation, Translation and Transformation: Dordrecht, Springer.

\section{Notes}

Note 1. At the TU Dresden teachers and students were first asked to complete the questionnaire regarding the evaluation of lectures and seminar since it has a long tradition at the TU Dresden. Almost all teachers and students know the instrument of lecture evaluation that has been used since 1998. Next, interviews were conducted. This order was also chosen due to the low level of willingness of teachers and students to participate in the interviews.

The KNRTU-KAI has no systematic experience of students' participation in quality management, but students have some notion about it because they were involved in the learning quality assessment processes during accreditation and external evaluation.

Note 2. Benchmarking is not given more attention because it is not a form of quality assurance at either university. It is not always possible or desirable to fix reference values in relation to quality objectives.

\section{Appendix A}

\section{Dear Teacher/Student!}

We are keen to hear your view in the survey "Students' opinion about teaching activities" (Questionnaire for Evaluating Lectures). Please, complete this form with the mark «X».

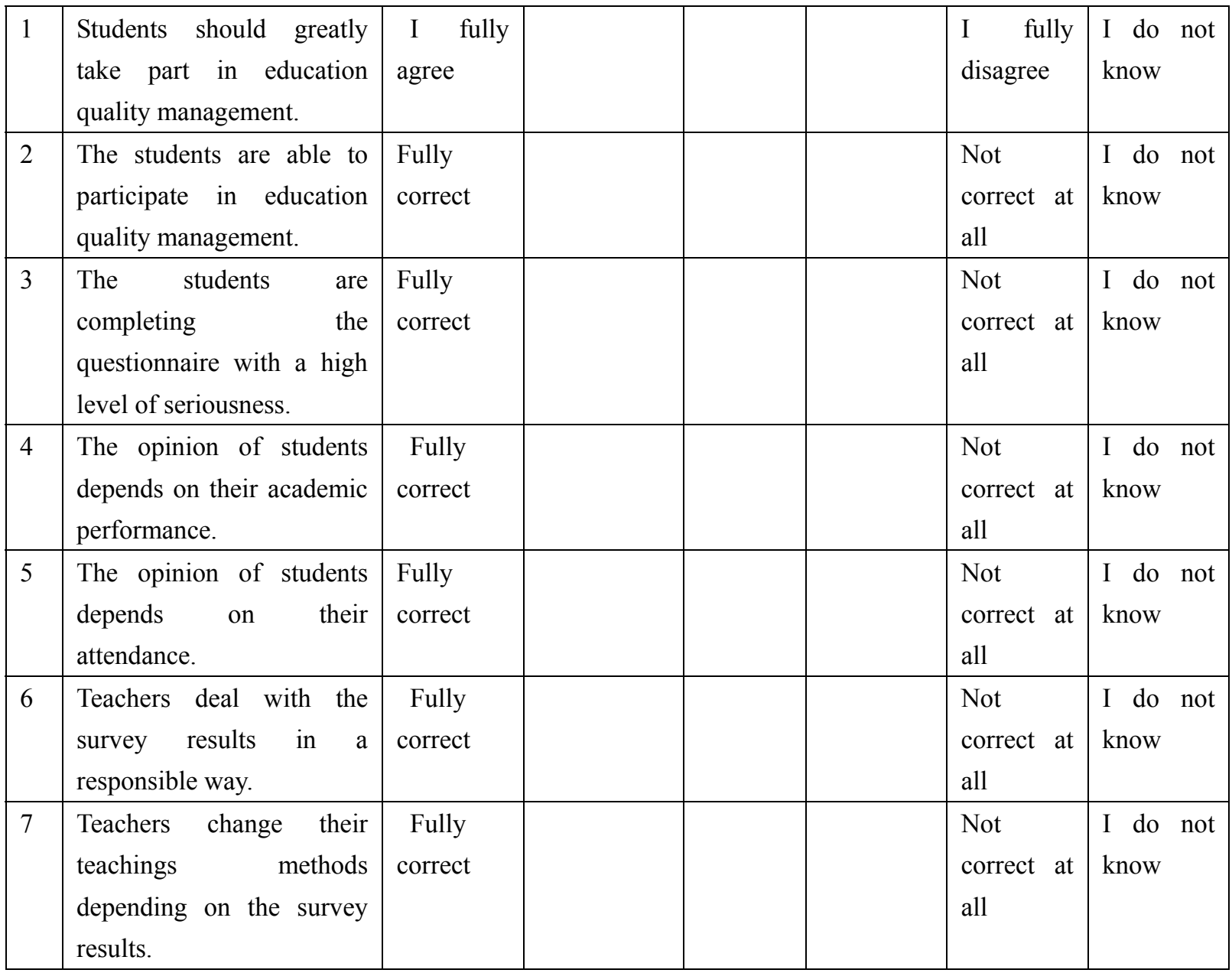




\begin{tabular}{|c|c|c|c|c|c|c|c|}
\hline 8 & $\begin{array}{l}\text { Teachers feel a lot of } \\
\text { stress/pressure according } \\
\text { to the survey results. }\end{array}$ & $\begin{array}{c}\text { Fully } \\
\text { correct }\end{array}$ & & & & $\begin{array}{l}\text { Not } \\
\text { correct at } \\
\text { all }\end{array}$ & $\begin{array}{l}\text { I do not } \\
\text { know }\end{array}$ \\
\hline 9 & $\begin{array}{l}\text { The results of the } \\
\text { evaluation affect the } \\
\text { education quality at the } \\
\text { university. }\end{array}$ & $\begin{array}{l}\text { Fully } \\
\text { correct }\end{array}$ & & & & $\begin{array}{l}\text { Not } \\
\text { correct at } \\
\text { all }\end{array}$ & $\begin{array}{l}\text { I do not } \\
\text { know }\end{array}$ \\
\hline 10 & $\begin{array}{l}\text { The faculty administration } \\
\text { deal with the survey results } \\
\text { in a responsible way. }\end{array}$ & $\begin{array}{l}\text { Fully } \\
\text { correct }\end{array}$ & & & & $\begin{array}{l}\text { Not } \\
\text { correct at } \\
\text { all }\end{array}$ & $\begin{array}{l}\text { I do not } \\
\text { know }\end{array}$ \\
\hline 11 & $\begin{array}{l}\text { The results of the } \\
\text { evaluation should effect } \\
\text { administration decisions } \\
\text { about a teacher. }\end{array}$ & $\begin{array}{l}\text { I fully } \\
\text { agree }\end{array}$ & & & & $\begin{array}{l}\text { I fully } \\
\text { disagree }\end{array}$ & $\begin{array}{l}\text { I do not } \\
\text { know }\end{array}$ \\
\hline 12 & $\begin{array}{l}\text { The salary of teachers } \\
\text { should depend on the } \\
\text { survey results. }\end{array}$ & $\begin{array}{l}\text { I fully } \\
\text { agree }\end{array}$ & & & & $\begin{array}{l}\text { I fully } \\
\text { disagree }\end{array}$ & $\begin{array}{l}\text { I do not } \\
\text { know }\end{array}$ \\
\hline 13 & $\begin{array}{l}\text { For whom should the } \\
\text { results of the evaluation be } \\
\text { available? }\end{array}$ & $\begin{array}{l}\text { For } \\
\text { anyone } \\
\text { interested }\end{array}$ & $\begin{array}{l}\text { Only for } \\
\text { students }+ \\
\text { teachers of } \\
\text { this course }\end{array}$ & $\begin{array}{l}\text { Only for } \\
\text { teachers }\end{array}$ & $\begin{array}{l}\text { Only for } \\
\text { teachers }+ \\
\text { administra } \\
\text { tion }\end{array}$ & $\begin{array}{l}\text { Only for } \\
\text { administra } \\
\text { tion }\end{array}$ & $\begin{array}{l}\text { I do not } \\
\text { know }\end{array}$ \\
\hline
\end{tabular}

Do you have further comments in relation to any of the questions above or any other aspects of the survey?

Your age

For teachers: Your number of years of teaching

For students: Your year of study

\section{Copyrights}

Copyright for this article is retained by the author(s), with first publication rights granted to the journal.

This is an open-access article distributed under the terms and conditions of the Creative Commons Attribution license (http://creativecommons.org/licenses/by/3.0/). 